\title{
TEKNIK PENGENALAN SUARA MUSIK PADA ROBOT SENI TARI
}

\author{
Indra Dwisaputra ${ }^{1}$, Ocsirendi $^{2}$ \\ 1,2Jurusan Teknik Elektro dan Informatika - Politeknik Manufaktur Negeri Bangka Belitung \\ Jl. Timah Raya Kawasan Industri Air Kantung Sungailiat, 0717-93586 \\ dwisaputra.indra@gmail.com
}

\begin{abstract}
The dancing robot has become an annual competition in Indonesia that needs to be developed to improve robot performance. The dancing robot is a humanoid robot that has 24 degrees of freedom. For 2018 the theme raised was "Remo Dancer Robot". Sound processing provides a very important role in dance robots. This robot moves dancing to adjust to the rhythm of the music. The robot will stop dancing when the music is mute. The resulting sound signal is still analogous. Voice signals must be changed to digital data to access the signal. Convert analog to digital signals using Analog Digital Converter (ADC). $A D C$ data is taken by sampling time 254 data per second. The sampling data is stored and grouped per 1 second to classify the parts of Remo Dance music. The results of data classification are in the form of digital numbers which then become a reference to determine the movement of the robot. Robots can recognize conditions when music is in a mute or a play condition.
\end{abstract}

Keywords: ADC, Humanoid Dancing Robot, Signal Processing

\section{Abstrak}

Robot senitarisudahmenjadi kompetisi tahunan di Indonesia yang perlu untuk dikembangkan dalam meningkatkan performa robot. Robot seni tari merupakan robot humanoid yang memiliki 24 derajat kebebasan. Untuk tahun 2018 tema yang diangkat adalah "Robot Penari Remo". Pengolahan suara memberikan peran yang sangat penting pada robot seni tari. Robot ini bergerak menari menyesuaikan dengan bagian irama musik. Robot akan berhenti menari saat musik pada kondisi bisu. Sinyal suara yang dihasilkan masih bersifat analog. Sinyal suara harus dirubah ke data digital untuk mengakses sinyal. Mengubah sinyal analog ke digital menggunakan Analog Digital Converter (ADC). Data ADC diambil dengan sampling time 254 data per detik. Data sampling disimpan dan dikelompokkan per 1 detik untuk mengklasifikasikan bagian-bagian dari musik Tari Remo. Hasil klasifikasi data berupa bilangan digital yang kemudian menjadi acuan untuk menentukan gerakan robot. Robot dapat mengenali kondisi saat musik dalam kondisi bisu.

Kata kunci: ADC, Robot Tari Humanoid, Pemroses Signal

\section{PENDAHULUAN}

Robot Seni tari mulai banyak dikembangkan di Indonesia sejak Kontes Robot Seni Tari Indonesia (KRSTI) mulai diselenggarakan. KRSTI merupakan suatu ajang kompetisi perancangan, pembuatan dan pemrograman robot yang disertai dengan unsur-unsur seni dan budaya bangsa Indonesia khususnya seni tari yang telah terkenal di bumi pertiwi. KRSI pertamakali diadakan pada tahun 2010 dengan tema "Robot Penari Jaipong", tahun 2011 dengan tema "Robot Penari Pendet", tahun 2012 dengan tema "Robot Penari Klono Topeng", tahun 2013 mengangkat tema "Robot Penari Piring", tahun 2014 mengangkat tema "Robot Penari Hanuman Duto", pada tahun 2015 mengangkat tema "Robot Penari Bambangan Cakil", pada tahun 2016 mengangkat tema "Robot Penari Topeng Betawi", pada tahun 2017 mengangkat tema "Robot Penari Gending Sriwijaya" (Panduan KRSTI 2018). Untuk KRSTI 2018, kembali guna membangkitkan kecintaan dan pelestarian budaya Nasional maka tema yang diangkat adalah "Robot Penari Remo".

Robot bergerak berdasarkan suara musik Tari Remo sehingga pengolahan data suara musik menjadi sangat penting. Pengembangan dan pemodelan sistem kendali melalui suara untuk lengan palsu telah dibuat dan diterapkan pada four-jointed arm robot. Hasil didapatkan penggunaan sistem kendali suara lebih efisien $11 \%$ namun membutuhkan prosessor yang besar dalam penyimpanan data perintah suara. (Koksal Gundogdu, 2017). Salah satu teknik mendeteksi musik adalah dengan cara beat detection menggunakan metode Infinite Impulse Respone, namun hasil menunjukan filter IIR bandpass tidak bisa bekerja dengan frekuensi cutoff dibawah $1 \mathrm{KHz}$. (Achmad Fausi, dkk. 2011). Sistem pengenalan irama 
musik dengan mengkombinasikan metode Filter Bank, Power Sinyal, Thresholding dan Feed Forward Artificial Neural Network (ANN). Penggunaan kombinasi beberapa metode pengolahan sinyal dengan ANN sudah cukup baik untuk menghasilkan keputusan gerakan tari. Berdasarkan pengujian pengolahan sinyal secara real time pada perangkat keras dan pengujian secara offline data real time pada ANN di PC, diperoleh hasil yang cukup baik dengan prosentase keberhasilan / akurasi 100\%. (Bima Sena, dkk, 2010). Pengenalan perintah suara terisolasi untuk mengendalikan navigasi robot dapat menggunakan Fast Fourier Transform (FFT). Hasil diperoleh robot dapat mengenali 70\% perintah suara. (Hooman Heidari, 2012).

Penelitian ini akan membahas tentang pengenalan suara musik dengan memanfaatkan pembacaan nilai Analog Digital Converter (ADC) dari output signal analog suara. Nilai ADC didapat dari sampling data yang cepat. Data ADC dikemudian di masukkan ke array dan disimpan. Data array diproses untuk ditentukan bagian musik dari Tari Remo. Hasil penentuan bagian musik tersebut akan diteruskan ke aktuator untuk digerakkan sesuai gerakan yang diinginkan.

\section{METODE PENELITIAN}

Penelitian ini bertujuan untuk melakukan analisis data pembacaan lagu Tari Remo pada Robot Seni Tari. Analisis yang dimaksud adalah mempelajari nilai data ADC yang didapat dari lagu tari Remo kemudian membuat bagian-bagian hasil pembacaan dalam array. Metode penelitian dilakukan eksperimen. Eksperimen yang dimaksud adalah pengujian langsung dilakukan pada robot yang sebenarnya. Perancangan sistem pada penelitian ini ada dua hal utama sistem hardware dan software.

\subsection{Desain Sistem Hardware}

Sistem hardware yang akan dibuat disesuaikan dengan spesifikasi sistem keseluruhan yang akan dibangun. Setiap Jenis hardware dipelajari spesifikasi dan teknis penggunaannya agar sesuai dan relevan terhadap satu sama lainnya. Adapun blok diagram hardware robot keseluruhan dapat dilihat pada gambar 1.

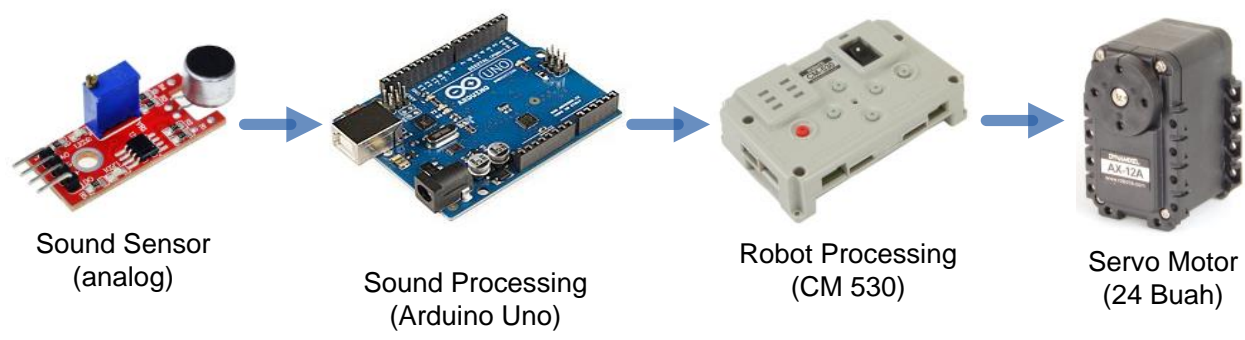

Gambar 1 Blok Diagram Hardware

Sensor suara yang digunakan adaalah sensor suara tipe analog sensor. Signal analog yang dihasilkan diolah menggunakan mikrokontroler tipe arduino Uno. Pemilihan Arduino Uno dikarenakan mikrokontroler ini sudah dilengkapi dengan pin ADC yang sesuai dengan sound sensor yang digunakan. Mikrokontroler jenis ini juga sudah dilengkapi dengan pin Tx Rx sebagai komunikasi serial pengiriman data dari Arduino ke CM 530 sebagai processing utama robot. CM 530 juga dilengkapi pin yang kompetibel dengan motor servo jenis Dynamixel. Komunikasi keduanya menggunakan Universal Asynchronous Receiver Transmitter (UART) ke Transistor-Transistor Logic (TTL).

\subsection{Desain Sistem Software}

Bagian ini membahas bagaimana metode dari menerima suara kemudian masuk ke pengolahan suara hingga ke keputusan gerakan robot. Adapun Blok diagram metode sistem software dapat dilihat pada gambar 2. 


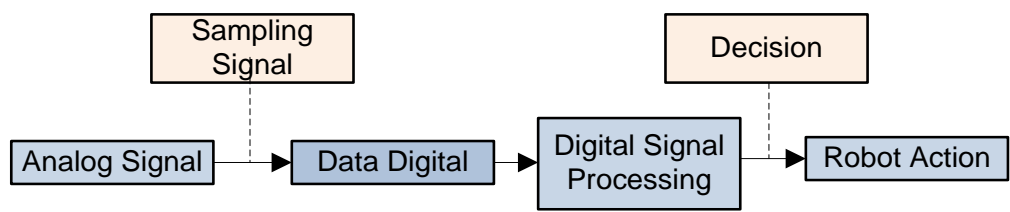

Gambar 2. Blok diagram sistem software

Signal analog didapat dari sensor suara yang membaca suara dari mikrophone. Dalam percobaan menggunakan lagu dari suara musik Tari Remo. Sampling time yang digunakan adalah 20ms. Setelah disampling menghasilkan data digital. Untuk mengetahui bagian-bagian dari lagu diolah melalui digital signal processing. Data hasil pengolahan kemudian dibagi-bagi dalam beberapa bagian sehingga dapat diputuskan untuk gerakan robot sesuai dengan yang diinginkan.

\section{HASIL DAN PEMBAHASAN}

\subsection{Pembacaan Signal ADC Kondisi Suara Musik}

Pengujian yang pertama kali dilakukan adalah pengambilan data ADC untuk pembacaan musik tari remo. Adapun blok diagram proses pembacaan signal ADC dapat dilihat pada gambar 3.

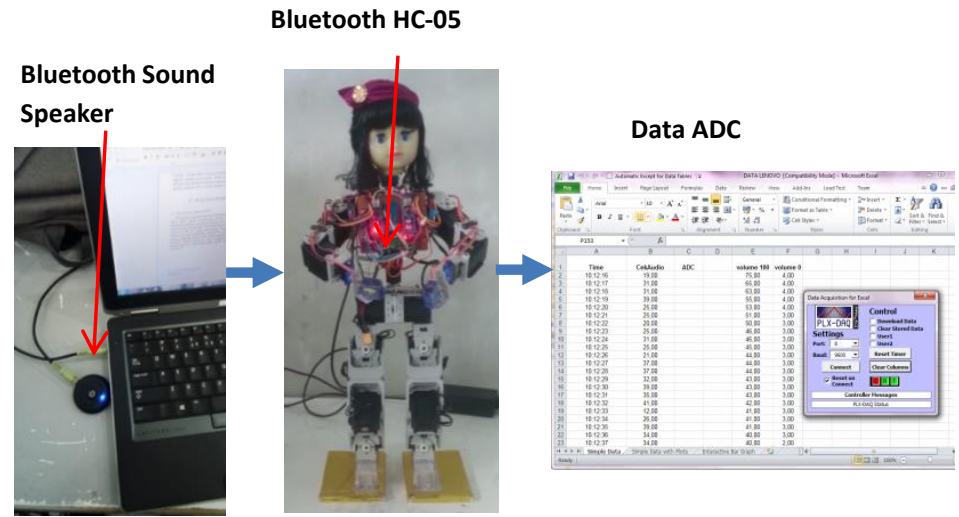

Gambar 3. Blok Diagram pembacaan data ADC

Pengujian dilakukan dengan menghubungkan jack sound laptop dengan modul bluetooth speaker. Data dari bluetooth dikirim ke modul bluetooth $\mathrm{HC}-05$ yang terhubung dengan mikrokontroler. Data nilai ADC yang diterima Bluetooth speaker diproses oleh mikrokontroler Arduino Nano. Data kemudian dikirimkan menggunakan komunikasi serial ke Microsoft Excel menggunkan software PLX-DAQ. Sample data diambil menggunakan sampling time frekuensi tinggi. Sampling time yang digunakan adalah 254 data per detik. Mikrokntroler menggunakan ADC 1024 byte yang mewakili tegangan 0-5 V. Perhitungan jumlah data untuk 3 menit lagu tari remo adalah sebagai berikut:

Jumlah Data $=60 \mathrm{~s} \times 3$ menit $\times 254$

Jumlah Data $=45720$ data

Dikarenakan jumlah data yang terlalu banyak tidak memungkinkan untuk ditampilkan seluruhnya. Dari data diatas dapat dilihat bahwa rentang nilai yang didapat adalah $0 \leq A D C \leq 179$. Masih banyaknya terdapat nilai 0 menyebabkan sulit untuk memutuskan apakah kondisi musik Tari Remo dalam keadaan mute atau play. Sehingga diperlukan pengolahan signal digital.Berikut dibawah ini adalah sample selama 4 detik. 


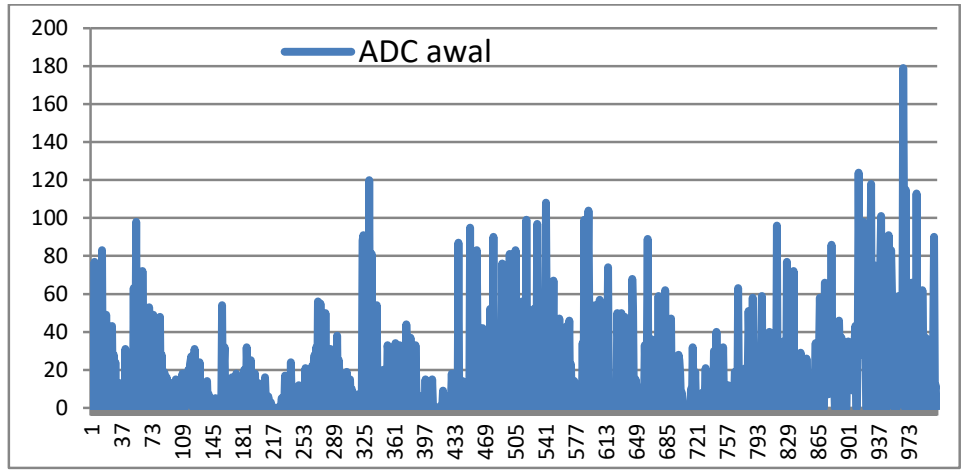

Gambar 4. Grafik Data ADC Tari Remo

Data dari sensor dilakukan menggunakan persamaan rata-rata. Penghitungan rata-rata dilakukan dengan menjumlahkan seluruh nilai data suatu kelompok sampel, kemudian dibagi dengan jumlah kelompok sampel tersebut. Jadi jika suatu kelompok sampel acak dengan jumlah saample $\mathrm{n}$ maka bisa dihitung rata-rata dari sampel tersebut dengan rumus sebagai berikut:

$\overline{\mathrm{x}}=\frac{1}{\mathrm{n}}\left(\mathrm{x}_{1}+\mathrm{x}_{2}+\cdots+\mathrm{x}_{\mathrm{n}}\right)$

$\bar{x}=\frac{1}{n} \sum_{i=1}^{n} x_{i}$

Keterangan:

$\bar{x}=$ rata - ratahitung

$x_{i}=$ nilaisampleke $-i$

$n=$ jumlahsample

Rata-rata diambil dengan jumlah 254 data. Sehingga menghasilkan sampling time setelah di olah adalah satu detik. Data hasil pengolahan rata-rata nilai ADC pada musik tari remo selama 3 menit ditunjukan pada gambar 4.3. Dari hasil pengambilan data ADC diatas dengan kondisi minimum saat musik berlangsung selama 3 menit adalah 7 dan maksimum adalah 75 . Sehingga rentang kerja $7 \leq A D C \leq 75$. Jika dirata-ratakan adalah 29,26. Karena data ADC adalah bilangan bulat maka dibulatkan 29.

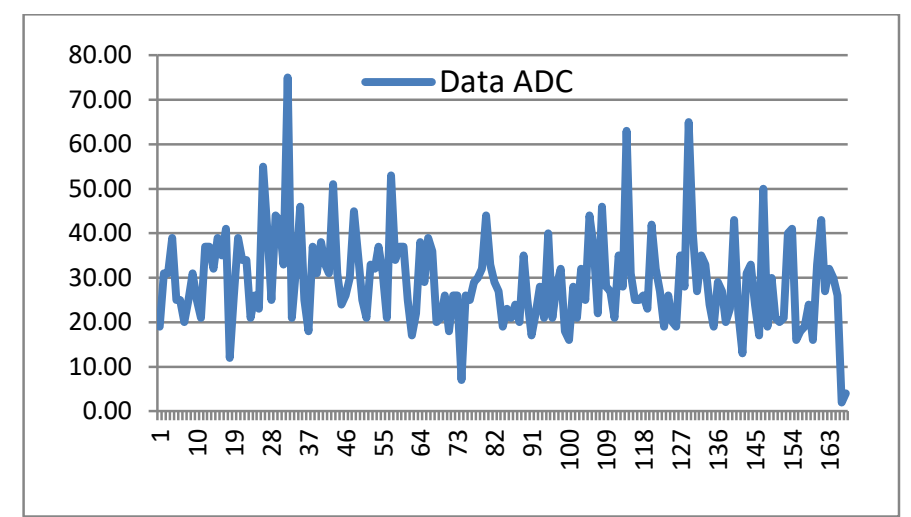

Gambar 5. Grafik Data ADC Tari Remo

\subsection{Pembacaan Signal ADC Kondisi Mute}

Pengujian berikutnya adalah pembacaan nilai ADC pada saat kondisi mute. Prosedur pengujian yang dilakukan sama dengan pengujian signal ADC kondisi suara musik. Hasil pengujian dapat dilihat pada gambar 3.4.Dari hasil pengambilan data ADC diatas dengan kondisi minimum saat mute berlangsung 
selama 3 menit adalah 1 dan maksimum adalah 4 . Sehingga rentang kerja $1 \leq A D C \leq 1$. Jika dirata-ratakan adalah 1,44. Karena data ADC adalah bilangan bulat maka dibulatkan 1.

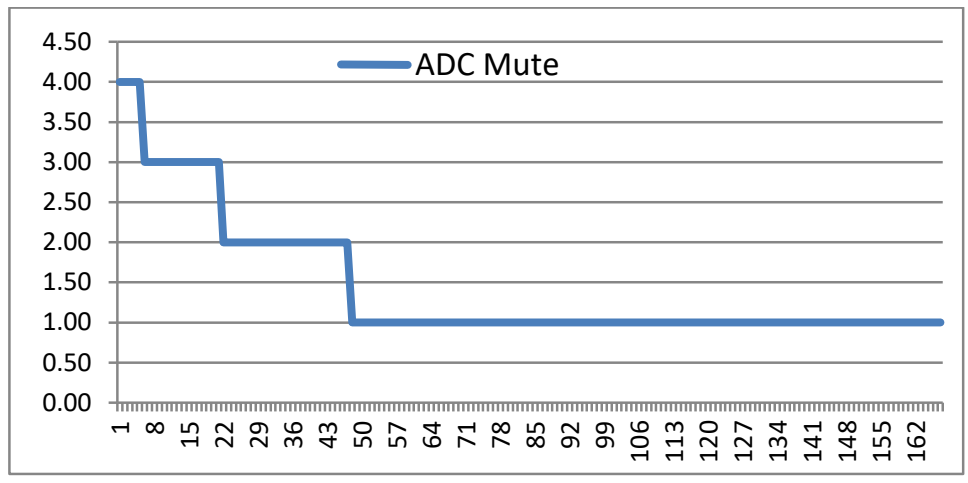

Gambar 6. Nilai ADC kondisi mute

\section{SIMPULAN}

Penelitian telah dilakukan sesuai dengan yang diharapkan. Adapun kesimpulan yang didapat dari hasil peneilitian ini adalah sebagai berikut:

1. Dengan sampling time 254 /detik nilai ADC tidak bisa langsung digunakan sebagai acuan ada tidaknya suara musik dikarenakan masih banyak ADC yang bernilai " 0 ".

2. Penggunaan rata-rata nilai $A D C$ per 1 detik efektif untuk meminimalisir nilai " 0 ” dari data $A D C$ suara musik.

3. Robot dapat membedakan antara kondisi mute dan play suara musik dengan membuat batasan nilai terendah untuk kondisi play yaitu kurang dari 7.

4. Robot dapat bergerak selama kondisi musik play dan berhenti bergerak selama kondisi musik mute

\section{DAFTAR PUSTAKA}

[1]. Kementrian Riset, Teknologi dan Pendidikan Tinggi, Buku Panduan Kontes Robot Seni Tari Indonesia 2018, 2018.

[2]. Achmad Fausi, Bima Sena Bayu, Fernando Ardilla, "Sistem Deteksi Musik Dengan Metode DeatDetection pada Arm Robot 4-DOF Berbasis TMS320VC5402", Politeknik Elektronika Negeri Surabaya, 2011.

[3]. Bima Sena, Ardik Wijayanto, "Sistem Identifikasi Ciri Musik untuk Robot Penari Jaipong", Politeknik Elektronika Negeri Surabaya, 2010.

[4]. Koksal Gundogdu, Sumeyye Bayrakdar, Ibrahim Yucedag, "Developing and modeling of voice control system for prosthetic robot arm in medical systems", Journal of King Saud University-Computer and Information Science.

[5]. Hooman Heidari, Suresh Gobee, "Isolated Word Command Recognition for Robot Navigation", Internasional Symposium on Robotics and Intelligent Sensors, 2012.

[6]. https://id.wikipedia.org/wiki/Robot_humanoid (diakses pada tanggl 27 Februari 2018)

[7]. https://id.wikipedia.org/wiki/Pemrosesan_sinyal_audio (diakses pada tanggl 27 Februari 2018)

[8]. Datasheet RTC DS1307 